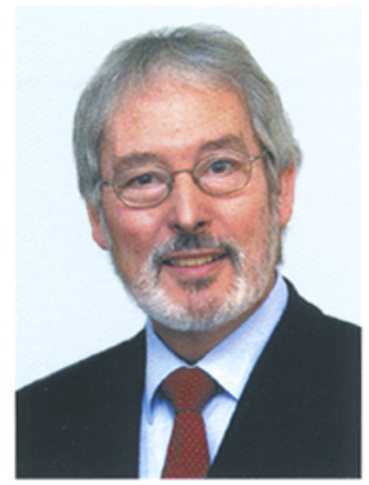

Rolf Harbeck

\section{Anerkennung, Dank, Glückwunsch}

Liebe Leserin, lieber Leser,

natürlich wissen Sie, dass Ihre Fachzeitschrift "Kartographische Nachrichten" heißt und sicher haben Sie auch den aktuellen Untertitel "Zeitschrift für Geoinformation und Visualisierung" vor Augen. Aber so richtig vertraut sind Ihnen doch die zwei Buchstaben: KN! Mit KN verbinden Sie ein immer noch grünes Heft, das Ihnen fachlich Neues aus der Kartographiewelt, Persönliches aus der kartographischen Gemeinschaft Osterreichs, Deutschlands und der Schweiz und Namentliches aus dem Kollegenkreis an den Arbeitsplatz oder in Ihre Lese-Ecke bringt. In der Tat: Namen und damit Menschen sind es, auf die Sie stets in Ihren KN auch stoßen: Im Literaturverzeichnis des Aufsatzteils, in den Mitteilungen aus den Gesellschaften, natürlich unter Persönliches und zuletzt im Impressum. Dort finden Sie die Personen, die hinter Ihren KN stehen und die eigentlich nicht in den Vordergrund gehören.

Bei diesem Heft ist das anders. Diesmal stellen wir es unter den Themenkreis "Fernerkundung und Kartographie" und widmen es einem Kollegen, der sich nicht nur um die Verbindung die- ser beiden Disziplinen, sondern auch um unsere Fachzeitschrift, um Ihre KN, verdient gemacht hat: Professor Dr. Jürgen Dodt, dem langiährigen Hauptschriftleiter und jetzigen Ehrenschriftleiter der Kartographischen Nachrichten. Er begeht am 3. Juni 2004 seinen 65. Geburtstag.

Unsere Fachzeitschrift erscheint im 54. Jahrgang, und dass dies ein Zeichen von Kontinuität ist und Verantwortung bedeutet, darauf konnte ich schon in einem der vorigen Hefte hinweisen. Doch dass die KN, nachgewiesenermaßen eines der weltweit ältesten Fachorgane für Kartographie, in dieser Kontinuität erscheinen konnte, ist Persönlichkeiten zu danken, die sich als ehrenamtliche Schriftleiter in den Dienst der fachlichen Publikation gestellt haben. Prominente und vertraute Namen finden sich darunter: Wolfgang Pillewizer, Werner Bormann, Oskar Stollt, Hans Ferschke - und seit 1988 eben Jürgen Dodt.

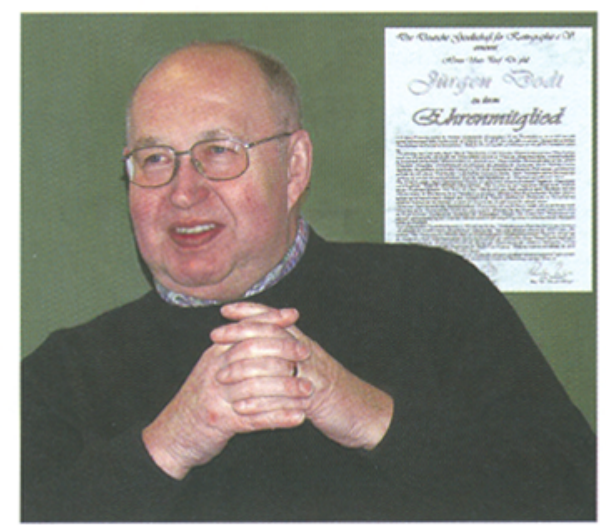

Wenn heute die mit knapp 2000 Mitgliedern nicht gerade zahlenstarke Deutsche Gesellschaft für Kartographie e.V. mit den $\mathrm{KN}$ sechsmal im Jahr ein 48 Seiten umfassendes Periodikum, dazu im Abstand von zwei Jahren das über 300 Seiten starke Kartographische Taschenbuch (KT) und schließlich die in neunter Folge erscheinenden Kartographischen Schriften (KS) herausgeben kann, dann ist dies vor allem ein Verdienst Jürgen Dodts. Mit Beharr- lichkeit und wissenschaftlicher wie journalistischer Kompetenz, mit fachlichem Gespür und bisweilen spitzer Feder hat er Entwicklungsnotwendigkeiten aufgezeigt und die Publikationsorgane der DGfK auf eine Linie ausgerichtet. Sie hat zu Verlagsprodukten geführt, die in inhaltlicher Substanz und äußerem Auftritt überzeugen und hohen Identifikationswert besitzen.

In dem Anliegen, diese Leistung zu würdigen, haben sich Mitarbeiter, Schüler und Kollegen Jürgen Dodts gerne bereit gefunden, Aufsätze aus seiner Themenwelt beizutragen und seinen beruflichen Lebensweg zu umreißen. Ulrich Freitag zeigt mit "Mapping the Global Village" die Rahmenbedingungen einer modernen, medienorientierten Kartographie auf. Über die Dokumentation des sabäischen Kulturerbes in der Republik Jemen mit Hilfe von Fernerkundungsdaten und topographischen Karten berichten Annette Hornschuch und Christiane Lechtenbörger. Mit dem „Digitalen Grubenriss-Informationssystem" als einem Instrument des Risikomanagements im Bergbau schlagen Harald Mark, Jürgen Schewe und Gerald Stein die Brücke zu Jürgen Dodis geographischem und umweltorientiertem fachlichen Wirkungskreis. Und von Jürgen Dodt stammt der Hinweis, Achim Roth und Jörn Hoffmann um Genehmigung zu bitten, ihren beim Kartographentag Bad Krozingen gehaltenen Vortrag "Die dreidimensionale Kartierung der Erde" abzudrucken.

So ist ein Themenheft entstanden, das mit seinem fachlichen Inhalt Jürgen Dodt zugeeignet ist und ihm gegenüber dies zum Ausdruck bringen will: Anerkennung, Dank und Glückwunsch! Ich wünsche Ihnen eine anregende Lektüre.

Herzlich, Ihr

\section{Tor LAOCuch}

